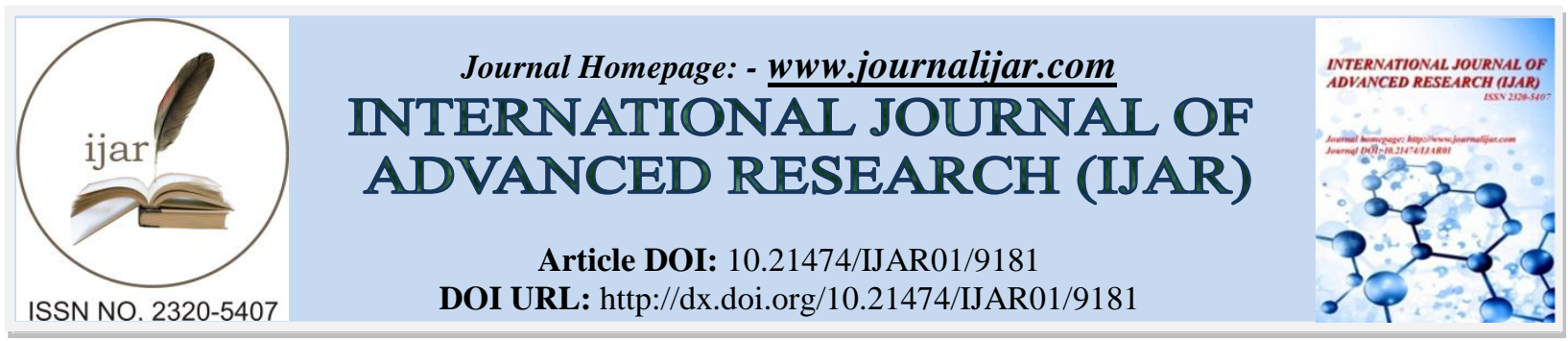

RESEARCH ARTICLE

\title{
DEPRESSION AND WORK-RELATED FACTORS AMONG NURSES WORKING AT MOI TEACHING AND REFERRAL HOSPITAL ELDORET, KENYA: A CROSS-SECTIONAL STUDY.
}

\author{
Zablon Nyaberi ${ }^{1}$ Juliah Nyamwata $^{2}$ and Machuki Isaac Ogoncho ${ }^{3}$. \\ 1. Masinde Muliro University of Science and Technology, Kakamega. \\ 2. Moi Teaching and Referral Hospital, Eldoret, Kenya. \\ 3. University of Kabianga, Kericho.
}

\section{Manuscript Info}

\section{Manuscript History}

Received: 26 March 2019

Final Accepted: 28 April 2019

Published: May 2019

Key words:-

Depression, Nursing, Stressors,

Adaptation.

\section{Abstract}

Objectives: To determine the relationship between work related factors and depression among nurses working at Moi Teaching and Referral Hospital.

Methods: A cross-sectional design was employed. Stratified sampling technique was used to select 281 participants from the population. A structured questionnaire was used to collect information on the sociodemographic characteristics of the nurses, Beck's Depression Inventory to assess the symptoms of depression among nurses and Interview Schedules with the heads of nursing departments on factors associated with depression among nurses. STATA version 13 was used to analyze data. Descriptive statistics was used to summarize the data. Bivariate and multivariate statistics was applied to examine relationships between dependent and independent variables. The findings were presented using tables and graphs. The study sought approval by MMUST Institutional Review Board and Institutional Research and Ethics committee of Moi Teaching and Referral Hospital, Moi University School of Medicine. Informed consent of participants was adhered to during the study.

Results: Work-related factors had a strong relationship with the depression status, these included education level, department, shift, income and religion. Majority of these variables showed a statistically significant relationship, i.e. education level had a $\mathrm{P}<0.002$, department had a $\mathrm{P}<0.014$, shift had a $\mathrm{P}<$ of 0.013 , income $\mathrm{P}<0.008$, responsibility $\mathrm{P}<0.001$ while work experience showed an insignificant relationship evidenced by the $\mathrm{P}<0.553$.

Conclusion: On the basis of the study findings, the researcher recommends that the policy makers at MTRH should formulate policies that will help prevent depression among nurses and improve service delivery

Copy Right, IJAR, 2019,. All rights reserved.

\section{Introduction:-}

Depression is a mental disorder characterized by sadness, lack of confidence, decreased energy, loss of confidence and self-esteem, sense of guilt, suicidal ideation, decreased concentration and inadequate pattern of sleep and 
appetite. It can be understood as a continuation of negative feelings and can lead to dysfunction of the individual(1). On the world stage, depression can be considered as a public health problem due to its high prevalence and to the functional disability that it causes(2).

The professionals who interact most part of the time with individuals in need of support are the most susceptible to mental illness(3). Among them, it is highlighted the nursing professionals who work directly with the intimacy, pain and fears that are part of the human suffering. Relationship problems in the work environment, difficulties of relocating, strenuous working days, system of shifts, as well as exposure to physical, chemical and biological agents equally constitute predisposing factors for the onset of depression(4). The relationship between depression and the worker is directly modulated by stressors in the work environment. Work stress, defined as a result of the imbalance between the demands of professional practice and worker's coping ability, is associated with professional strain, negatively affecting the mental health of workers.

Poor mental health among nurses not only hinders professional performance but also affects the quality of healthcare provided. Nurses are indispensable to the healthcare system and their well-being and work performance has a considerable effect on the quality of hospital healthcare. Nursing is invariably considered a stressful occupation within the healthcare system, and nurses experience a variety of occupational stressors.

Being in the medical field, nurses are faced with heavier pressure and psychological stressors and medical practice. They are at a higher risk for depression as other professions in the same field (5).Nurses are likely to come up with occupational stress and the ambiguities of the profession, who most directly and frequently interact with patients and affect those patients by their behavior and attitudes. Therefore, their wellbeing cannot be taken lightly. Some studies have indicated that depression may decrease the function of nurses and disturbs the nurse-patient's relationship (6). Depression among nurses has attracted great attention from hospital and society. There are limited studies on depression regarding prevalence and correlates among nurses in Kenya.

In Kenya, there is limited evidence relating to mental health problems among nurses. There are no reported studies that investigate the relationship between stress, anxiety and depression among nurses, and researchers have paid little attention toward factors associated with mental health problems. Therefore, the findings of this study could be used in nursing profession and counseling activities. Owing to a paucity of data, this study aimed to examine the relationship between depression and socio demographic characteristics.

\section{Research Methodology}

This study applied a cross-sectional research design. The design involved the collection of data at one point in time. Phenomena under study are captured during one period of data collection. This design is appropriate for describing the status of phenomena or for describing relationships among phenomena at a fixed point in time. One can test the hypothesis, using cross-sectional data(7).

Cross-sectional data can most appropriately be used to infer time sequence under two circumstances; when there is evidence or logical reasoning indicating that one variable preceded the other and when a strong theoretical framework guides the analysis. Cross-sectional studies can also be used to infer about processes evolving over time. Cross-sectional studies are easy to do and are relatively economical (ibid).

The study was conducted at Moi Teaching and Referral Hospital which is located in Eldoret town, 310 kilometers Northwest of Nairobi. Nurses working at Moi Teaching and Referral Hospital constituted the study population. The number of nurses working in this hospital is 1050 . These nurses work in various departments in the hospital. Both male and female nurses are employed by the hospital and they work on different shifts. The male nurses are 164 and females are 886.

Beck's Depression inventory (BDI-II) was used to collect data on the dependent variable. The Beck's Depression Inventory (BDI) is a 21-item; self-report rating inventory that measures characteristic attitudes and symptoms of depression (8).

A score of 1-10 is considered normal, 11-16 is mild mood disturbance, 17-20 is borderline clinical depression, 21-30 is moderate depression, 31-40 is severe depression and over 40 is extreme depression. A persistent score of 17 or above indicates that one may require medical treatment. A structured questionnaire incorporating socio demographic 
was used to harvest data on study participants. Socio-demographic characteristics included age, gender, marital status, level of education and religion. The STATA statistical software was used to analyze the data. Descriptive statistics was used to summarize the data. Bivariate and multivariate statistics was applied to examine relationships between the independent and dependent variables. The findings were presented using tables.

\section{Results:-}

\section{Socio demographic Characteristics}

From the results, it was observed that the majority143 (51.07\%) of the respondents were aged 30-39 and 71 $(25.36 \%)$ of the respondents were aged 20-29 years. Less than a quarter of the respondents, $45(16.07 \%)$ were aged $40-49$ years while only $21(7.5 \%)$ of the respondents were aged above 50 years. This meant that the study was not biased in terms of age representation of its sample population that was key for this study.

More than half $170(60.93 \%)$ of the respondents had diploma level of education, slightly less than a quarter, $64(22.94 \%)$ of the respondents had attained degree level of education, $40(14.34 \%)$ of the respondent had attained certificate level of education while only $5(1.79 \%)$ had attained masters level.

Seven in ten $205(73.68 \%)$ of the respondents were married, 11(3.93\%) of the respondents were widowed, $61(21.79 \%)$ of the respondents were single while only $3(1.58 \%)$ of the respondents were divorced or separated. By gender there was no big difference in the proportion for those who are married, single and divorced.

Table 1:- Socio demographic Characteristics

\begin{tabular}{|c|c|c|c|c|c|c|}
\hline \multirow[b]{2}{*}{ Background characteristics } & \multicolumn{2}{|c|}{ Total } & \multicolumn{2}{|c|}{ Females } & \multicolumn{2}{|c|}{ Males } \\
\hline & $\mathrm{N}$ & $\%$ & $\mathrm{n}$ & $\%$ & $\mathrm{~N}$ & $\%$ \\
\hline \multicolumn{7}{|l|}{ Age (years) } \\
\hline $20-29$ years & 71 & $25.36 \%$ & 42 & $22.11 \%$ & 29 & $32.22 \%$ \\
\hline 30-39years & 143 & $51.07 \%$ & 96 & $50.53 \%$ & 47 & $52.22 \%$ \\
\hline $40-49$ years & 45 & $16.07 \%$ & 33 & $17.37 \%$ & 12 & $13.33 \%$ \\
\hline$>50$ years & 21 & $7.5 \%$ & 19 & $10.00 \%$ & 02 & $2.22 \%$ \\
\hline Total & 280 & $100 \%$ & 190 & $100 \%$ & 90 & $100 \%$ \\
\hline \multicolumn{7}{|l|}{ Education } \\
\hline Certificate & 40 & $14.34 \%$ & 27 & $14.21 \%$ & 13 & $14.61 \%$ \\
\hline Diploma & 170 & $60.93 \%$ & 112 & $58.95 \%$ & 58 & $65.17 \%$ \\
\hline Degree & 64 & $22.94 \%$ & 48 & $25.26 \%$ & 16 & $17.98 \%$ \\
\hline \multirow[t]{2}{*}{ Masters } & 5 & $1.79 \%$ & 3 & $1.58 \%$ & 2 & $2.25 \%$ \\
\hline & 279 & $100 \%$ & 190 & $100 \%$ & 89 & $100 \%$ \\
\hline \multicolumn{7}{|l|}{ Marital status } \\
\hline Married & 205 & $73.21 \%$ & 140 & $73.68 \%$ & 65 & $72.22 \%$ \\
\hline Widowed & 11 & $3.93 \%$ & 11 & $5.79 \%$ & 0 & $0 \%$ \\
\hline Single & 61 & $21.79 \%$ & 36 & $18.95 \%$ & 25 & $27.78 \%$ \\
\hline Divorced/separated & 3 & $1.07 \%$ & 3 & $1.58 \%$ & 0 & $0 \%$ \\
\hline Total & 280 & $100 \%$ & 190 & $100 \%$ & 90 & $100 \%$ \\
\hline
\end{tabular}

\section{Depression and work related factors}

\section{Department of duty and depression}

Surgery, medicine, reproductive health and accidents and emergency showed a higher prevalence rate of depression (77\%) compared to the pediatrics. There was a statistically significant relationship between the department of duty and depression level $\left(\mathrm{p}=0.014, x^{2}=85.8392\right)$. The study findings were in agreement with those at Kenyatta National Hospital (KNH, 2012), which found out that most departments with heavy workload such as medical, and surgical wards registered high number of staff on sick and emergency leaves. This in turn compromised quality of patient care as some wards on frequent basis had one nurse reporting on duty against the recommended 6 to care for patients. Such happenings have been suspected to be as a result of stress and burn out. Gong, et al., (2014) concurred with the findings of this study, that nurses working in the internal medicine, intensive care unit (ICU), surgery, ear nose and throat (ENT) and paediatrics departments were more prone to depressive symptoms than those who worked in the departments of psychiatry, traditional Chinese medicine, rehabilitation, and administration (9). 
Table 2: Department of duty and depression

\begin{tabular}{|c|c|c|c|c|c|c|c|}
\hline \multicolumn{2}{|l|}{ Variables } & \multicolumn{3}{|c|}{ Depression levels (\%) } & \multirow[b]{2}{*}{$\begin{array}{l}\text { Moderat } \\
\mathrm{e}\end{array}$} & \multirow[b]{2}{*}{$\begin{array}{l}\text { Sever } \\
\mathrm{e}\end{array}$} & \multirow[b]{2}{*}{$\begin{array}{l}\text { Extrem } \\
\text { e }\end{array}$} \\
\hline & $\begin{array}{l}\text { Freq } \\
\text { (n) }\end{array}$ & $\begin{array}{l}\text { Norma } \\
1\end{array}$ & $\begin{array}{ll}\text { Mild } & \text { mood } \\
\text { disturbance }\end{array}$ & $\begin{array}{l}\text { Borderlin } \\
\mathrm{e}\end{array}$ & & & \\
\hline \multicolumn{8}{|l|}{ Department } \\
\hline Surgery & 91 & 5 & 7 & 57 & 29 & 2 & 0 \\
\hline Medicine & 71 & 3 & 3 & 51 & 39 & 3 & 1 \\
\hline Reproductive health & 50 & 8 & 12 & 48 & 30 & 0 & 2 \\
\hline Paediatrics & 43 & 47 & 35 & 14 & 2 & 2 & 0 \\
\hline $\begin{array}{ll}\text { Accidents } & \& \\
\text { Emergency } & \end{array}$ & 23 & 4 & 9 & 70 & 17 & 0 & 0 \\
\hline ICU/HDU & 1 & 0 & 0 & 0 & 100 & 0 & 0 \\
\hline Total & 280 & & & 77 & & & \\
\hline & & & $\chi^{2}=85.8392$ & $\mathrm{P}=0.014$ & & & \\
\hline
\end{tabular}

1) Work experience and depression

There was no statistically significant difference in the prevalence of the levels of depression and work experience among the nurses $(\mathrm{p}<0.553,13.6352)$ which was greater than the threshold value. The study differed with that by Shamaila, (2010), who reported that nurses with 5-9 years' length of service had the highest prevalence (71.3\%) of depression. Nurses with 10-14 years' length of service had the highest severity of depression (66.7\%) (10).

Table 3 Work experience and depression

\begin{tabular}{|l|l|l|l|l|l|l|l|l|}
\hline Variables & \multicolumn{2}{l|}{ Depression levels (\%) } & & & \\
\hline & Freq (n) & Normal & Mild mood disturbance & Borderline & Moderate & Severe & Extreme \\
\hline Less than 2years & 24 & 46 & 8 & 8 & 38 & 0 & 0 \\
\hline 2-4yrs & 96 & 28 & 15 & 26 & 26 & 3 & 2 \\
\hline 4-6yrs & 72 & 29 & 14 & 28 & 28 & 1 & 0 \\
\hline More than 6yrs & 89 & 34 & 10 & 30 & 25 & 1 & 0 \\
\hline Total & 281 & & & 56 & & & \\
\hline & & & $\chi^{2}=\mathbf{1 3 . 6 3 5 2}$ & P =0.553 & & & \\
\hline
\end{tabular}

\section{Duty shift and depression}

Table 4.6 shows a statistically significant relationship between shift and depression levels of the respondents $\left(\mathrm{p}<0.013, x^{2}=43.3453\right)$. Gong, et al., (2014) concurred with the findings of this study which indicated that nurses who worked more than 8 hours shift as well as those who worked two or more night shifts per week were at greater risk of experiencing depressive symptoms, confirming the findings of previous studies which had demonstrated a significant positive association between long working hours, frequent shift work and depressive symptoms (9).

Table 4: Duty shift and depression

\begin{tabular}{|c|c|c|c|c|c|c|c|}
\hline \multicolumn{2}{|l|}{ Variables } & \multicolumn{3}{|c|}{ Depression levels (\%) } & \multirow[b]{2}{*}{ Moderate } & \multirow[b]{2}{*}{ Severe } & \multirow[b]{2}{*}{ Extreme } \\
\hline & Freq $(n)$ & Normal & Mild mood disturbance & Borderline & & & \\
\hline \multicolumn{8}{|l|}{ Shift } \\
\hline 6hrs shift & 61 & 30 & 11 & 21 & 36 & 2 & 0 \\
\hline 8hrs shift & 92 & 37 & 17 & 22 & 22 & 1 & 1 \\
\hline 12hrs shift & 122 & 30 & 10 & 32 & 26 & 2 & 1 \\
\hline 6hrs \& 8hrs shift & 2 & 0 & 0 & 0 & 50 & 50 & 0 \\
\hline \multirow[t]{2}{*}{ Total } & 279 & & & 55 & & & \\
\hline & & & $\chi^{2}=43.3453$ & $\mathrm{P}=0.013$ & & & \\
\hline
\end{tabular}

2) Income and depression

Table 4.7 shows a higher prevalence $(86 \%)$ of the levels of depression levels among the nurses who earned low income compared to those who had higher income levels. The study further showed a statistically significant relationship between depression and income $\left(\mathrm{p}<0.008, x^{2}=92.6689\right)$. 
Table 5: Income and depression

\begin{tabular}{|c|c|c|c|c|c|c|c|}
\hline \multicolumn{2}{|l|}{ Variables } & \multicolumn{3}{|c|}{ Depression levels (\%) } & \multirow[b]{2}{*}{ Moderate } & \multirow[b]{2}{*}{ Severe } & \multirow[b]{2}{*}{ Extreme } \\
\hline & Freq $(n)$ & Normal & Mild mood disturbance & Borderline & & & \\
\hline \multicolumn{8}{|l|}{ Income } \\
\hline $20,000-30,000$ & 40 & 5 & 10 & 25 & 58 & 0 & 3 \\
\hline $30,000-40,000$ & 82 & 48 & 35 & 10 & 6 & 1 & 0 \\
\hline $40,000-50,000$ & 68 & 59 & 28 & 10 & 3 & 0 & 0 \\
\hline$>50,000$ & 90 & 59 & 23 & 10 & 4 & 2 & 1 \\
\hline Total & 280 & & & 26 & & & \\
\hline & & & $\chi^{2}=92.6689$ & $\mathrm{P}=0.008$ & & & \\
\hline
\end{tabular}

3) Responsibility and depression

Table 4.8 shows that the majority of the primary health care nurses showed the symptoms of depression more. The overall prevalence of depression for responsibility was high $(80 \%)$. Moreover, this study showed a statistically significant relationship between responsibility and depression levels $\left(\mathrm{p}<0.001, x^{2}=77.7121\right)$.

Table 6: Responsibility and depression

\begin{tabular}{|c|c|c|c|c|c|c|c|}
\hline \multicolumn{2}{|l|}{ Variables } & \multicolumn{3}{|c|}{ Depression levels (\%) } & \multirow[b]{2}{*}{$\begin{array}{l}\text { Moderat } \\
\mathrm{e}\end{array}$} & \multirow[b]{2}{*}{$\begin{array}{l}\text { Sever } \\
\mathrm{e}\end{array}$} & \multirow[b]{2}{*}{$\begin{array}{l}\text { Extrem } \\
\mathrm{e}\end{array}$} \\
\hline & $\begin{array}{l}\text { Freq } \\
(\mathrm{n})\end{array}$ & $\begin{array}{l}\text { Norma } \\
1\end{array}$ & $\begin{array}{ll}\text { Mild } & \text { mood } \\
\text { disturbance }\end{array}$ & $\begin{array}{l}\text { Borderlin } \\
\text { e }\end{array}$ & & & \\
\hline \multicolumn{8}{|l|}{ Responsibility } \\
\hline Primary nurse & 249 & 6 & 5 & 49 & 37 & 2 & 1 \\
\hline $\begin{array}{l}\text { Deputy nurse in- } \\
\text { charge }\end{array}$ & 17 & 41 & 41 & 6 & 6 & 6 & 0 \\
\hline Nurse in-charge & 10 & 40 & 60 & 0 & 0 & 0 & 0 \\
\hline Nurse Manager & 2 & 50 & 50 & 0 & 0 & 0 & 0 \\
\hline Total & 279 & & & 80 & & & \\
\hline & & & $\chi^{2}=77.7121$ & $\mathrm{P}=0.001$ & & & \\
\hline
\end{tabular}

B. Determinants (factors associated with) of depression

Table 7 presented the determinants of depression and its associated factors, that are significant in the area of study.

Table 7; Ordinal logistic regression model for determinants of depression

\begin{tabular}{|l|l|l|l|l|}
\hline Depression levels & Odds Ratio & Std. Err. & $\mathbf{Z}$ & $\mathbf{P}>\mathbf{Z}$ \\
\hline Income & 1.112661 & .1315646 & 0.90 & 0.367 \\
\hline Department & .9368018 & .0811421 & -0.75 & 0.013 \\
\hline Shift & 1.776195 & .1209396 & -1.13 & 0.010 \\
\hline Responsibility & 1.9168383 & .2081837 & -0.38 & 0.002 \\
\hline Work experience & .9231574 & .0884288 & -0.83 & 0.404 \\
\hline
\end{tabular}

\section{Responsibility and depression}

In this study, it was evidenced that responsibility was one of the risk factors for depression among nurses in Kenya. Findings of these study indicated that those who were working as primary caregiver nurses showed symptoms of depression compared to deputy nurses, department nurse in-charges and the nurse managers $(\mathrm{OR}=1.9168, \mathrm{p}<0.002)$.

\section{Duty shift and depression}

Findings from this study showed that nurses who worked the 12-hour shift had increased chances of being depressed compared to those who worked on the 8-and 6-hour shifts $(\mathrm{OR}=1.766, \mathrm{p}<0.010)$, implying that shift (working hours) was an important contributing factor that could lead to depression among nurses in Kenya.

\section{Discussion:-}

It is evident, that work-related factors have a strong relationship with the depression status. Some of the workrelated factors in this study include, department, shift, income and religion. Majority of these variables showed a statistically significant relationship, i.e., department had a p-value of 0.014 , shift had a p-value of 0.013 , income $\mathrm{p}$ - 
value of 0.008 , responsibility with p-value 0.001 while work experience showed an insignificant relationship evidenced by the p-value of 0.553 which is greater than the threshold value of 0.05 . These findings were similar to a number of studies conducted by different scholars: Gong, et al., (2014) concurs with the study findings that nurses working in the internal medicine, ICU, surgery, ENT and paediatrics departments were more prone to depressive symptoms than those who work in the departments of psychiatry, traditional Chinese medicine, rehabilitation, and administration. (KNH Data 2012) states that most departments with heavy workload- (the medical and surgical wards) register high number of staff on sick leave and emergency leave. This in turn compromises quality of patient care as some wards on frequent basis have one nurse reporting on duty against sixty plus patients to care for. Such happenings have been suspected to be as a result of stress and burn out.

In relation to the work related factors, shift was one of the determinants of depression where the staff who worked more than $8 \mathrm{hrs}$ shift showed symptoms of depression compared to those who worked 6hrs and 8hrs shift, responsibility was another determinant, where the staff who were primary care givers showed higher symptoms of depression compared to the rest of the staff.

\section{Conclusions:-}

In conclusion, the study revealed that there is a strong relationship between depression and work-related factors. The work-related factors that included working department, number of hours and type of shift, income level and responsibilities held by nurses had a strong relationship with depression.

In conclusion, work related factors had a strong relationship with depression.

\section{Recommendations:-}

1. Continuous mentorship to the young nurses' o best practices in handling their services.

2. Reduce the working shifts to $8 \mathrm{hr}$ and $6 \mathrm{hr}$ shift for the primary nurses.

3. The management should introduce Continuous Medical Education (CMEs) sessions to address the gaps identified in the long run this will be able to bring the young nurses up to speed with their work and improve performance.

4. Formulation of policies that will help prevent depression among nurses working at the hospital this will then improve service delivery and patients' wellbeing.

\section{References:-}

1. Manetti ML, Marziale MHP. Aspects associated to work-related depression on nursing staff. Estudos de Psicologia (Natal). 2007;12(1):79-85.

2. WHO. Revised global burden of disease (GBD) 2002 estimates. Genebra: World Health Organization. 2005.

3. Baba VV, Galperin BL, Lituchy TR. Occupational mental health: a study of work-related depression among nurses in the Caribbean. International journal of nursing studies. 1999;36(2):163-9.

4. Mark G, Smith AP. Occupational stress, job characteristics, coping, and the mental health of nurses. British journal of health psychology. 2012;17(3):505-21.

5. Ibrahim AK, Kelly SJ, Adams CE, Glazebrook C. A systematic review of studies of depression prevalence in university students. Journal of psychiatric research. 2013;47(3):391-400.

6. Uras C, Gennaro R, Aparo U, Tabolli S. Risk of anxiety and depression in nurses in Rome (Italy). Igiene e sanita pubblica. 2012;68(4):555-64.

7. Mugenda O, Mugenda J. Research methods. Qualitative and Quantitative Approaches. 2003.

8. Beck AT. Depression: Clinical, experimental, and theoretical aspects: University of Pennsylvania Press; 1967.

9. Gong Y, Han T, Yin X, Yang G, Zhuang R, Chen Y, et al. Prevalence of depressive symptoms and work-related risk factors among nurses in public hospitals in southern China: a cross-sectional study. Scientific reports. 2014;4:7109.

10. Shamaila K, Irfan U, Sheikh S, Faisal M. Frequency of stress and depression in female nurses working in a teaching hospital. Kust Med J. 2010;2:10-4. 